\title{
La fragmentación socioespacial de las urbanizaciones populares en la periferia de la ciudad de Culiacán Rosales
}

\author{
Belén Obdulia Pérez Peñuelas ${ }^{1}$ | Edith Rosario Jiménez Huerta ${ }^{2}$
}

Recibido: 10-06-2019 | en su versión final: 08-01-2020

Resumen

\begin{abstract}
El objetivo de este artículo es analizar la fragmentación socioespacial de las urbanizaciones populares en la periferia, como unidad poblacional predominante en la ciudad intermedia de Culiacán Rosales, capital del estado de Sinaloa. Se investigó a partir de datos cuantitativos, material cartográfico, censal e información de funcionarios de instancias gubernamentales. A partir de imágenes de satélite de Google Earth y recorridos de campo se elaboraron mapas temáticos georreferenciados empleando el software libre QGIS. El punto de partida del estudio consistió en la caracterización de los tipos de urbanizaciones populares en la periferia de la ciudad. En dos terceras partes de la superficie de la ciudad predominan diversos tipos de urbanizaciones populares: fraccionamientos, colonias, asentamientos de origen irregular y poblados o localidades rurales. Aunque estén contiguos, no se integran. Cada uno está delimitado, lo que da lugar a una particular fragmentación socioespacial de la periferia de la ciudad. Los fraccionamientos son la modalidad con más elementos divisorios, colocados por los promotores como parte de la mercadotecnia. El interés de gran parte de los estudios urbanos se ha centrado en las grandes metrópolis, en particular en los fraccionamientos insulares de la periferia. Son pocos los estudios que abordan el tema de las urbanizaciones populares y aún menos los que analizan la fragmentación en ciudades intermedias. El presente estudio visibilizó la diversidad de las urbanizaciones populares con hincapié en la importancia de identificarlos, de analizar su distribución y el importante papel que esta diversidad juega en la fragmentación socioespacial de la ciudad.
\end{abstract}

Palabras clave: Fragmentación urbana; unidad poblacional; ciudad intermedia

Citación

Pérez, B. y Jiménez, E. (2020). La fragmentación socioespacial de las urbanizaciones populares en la periferia de la ciudad de Culiacán Rosales. ACE: Architecture, City and Environment, 14(42), 8521. DOI: http://dx.doi.org/10.5821/ace.14.42.8521

\footnotetext{
${ }^{1}$ Arquitecta, Maestra en Arquitectura y urbanismo, por la Universidad Autónoma de Sinaloa. Alumna del programa de Doctorado en Ciudad, Territorio y Sustentabilidad de la Universidad de Guadalajara (ORCID: 0000-0002-2231-5420), 2 Profesora investigadora de la Universidad de Guadalajara. Investigadora del Sistema Nacional de Investigadores, Nivel II (ORCID: 0000-0002-1636-9326). Correo de contacto: arq.belenperez@gmail.com
}

ACE, 14 (42) CC BY-ND 3.0 ES | UPC Barcelona, España | La fragmentación socioespacial de las urbanizaciones populares en la periferia de la ciudad de Culiacán Rosales. DOI: http://dx.doi.org/10.5821/ace.14.42.8521 


\title{
Socio-spatial fragmentation of popular urbanizations on the outskirts of the city of Culiacan Rosales
}

\begin{abstract}
The aim of this article is to provide an analysis of the socio-spatial fragmentation of popular urbanisations on the edge of Culiacán Rosales, the state capital of Sinaloa, which are the main form of housing in this intermediate city. Research was conducted on the basis of quantitative data, cartographic material, census information and interviews with officials in government offices. With satellite images from Google Earth and through field-work, georeferenced thematic maps were elaborated using the free software of QGIS. The project began with a classification of the different types of popular urbanisations on the periphery of the city. The main form of housing in two thirds of the city as a whole, is that of various types of popular urbanisation: there are social housing developments built by private companies (fraccionamientos), neighbourhoods of self-built housing on formally subdivided land (colonias), originally informal settlements (asentamientos de origen irregular), and villages (poblados) or rural townships (localidades rurales). Although they are adjacent, they do not mix, which leads to a particular socio-spatial fragmentation of the periphery of the city. Real estate subdivisions are the type with the most barriers, placed by the developers as paet of their merchandising. Most urban studies have concentrated on the big metropolitan centres, and especially on the insular social housing estates (fraccionamientos) of the periphery. Few studies have taken up the subject of popular urbanisations and even less have analysed the fragmentation seen in intermediate cities. The study presented here has made the diversity of popular urbanisations more visible, with an emphasis on the importance of identifying the different types, studying their distribution, and explaining the important role their variety plays in the sociospatial fragmentation of the city.
\end{abstract}

Keywords: Urban fragmentation; neighbourhood; medium-sized city

\section{Introducción}

América Latina y el Caribe forman la región más urbanizada, donde casi el $80 \%$ de la población vive en ciudades. Esta acelerada urbanización estuvo marcada por la desigualdad social. Recientemente, las autoridades de los diferentes países de dicha región han implementado estrategias para desacelerar la expansión urbana y mejorar las condiciones de quienes ya habitan en las ciudades con características similares. En vista de que dos terceras partes de la riqueza se concentra en pocas áreas metropolitanas, se han estado diseñando políticas para evitar la concentración urbana en pocas urbes. Una de ellas consiste en ampliar el abanico de ciudades que contribuyan a la riqueza de la región, lo que se traduce en fomentar el desarrollo de centros urbanos secundarios, por lo que se prevé que estos seguirán expandiéndose. Por ello, las ciudades medias/intermedias están hoy en la mira del mercado inmobiliario. De ahí que la problemática urbana que se ha estado gestando -si no se atiende debidamente por las autoridades competentes- permanecerá y se agravará (ONUHÁBITAT, 2012).

Hay rasgos de la morfología de las ciudades latinoamericanas que caracterizan la expansión de las ciudades, como la dispersión y desconexión física entre sus partes. Estos nuevos rasgos afectan la planeación y distribución de servicios e infraestructura, encareciéndolos y haciéndolos ineficientes, generan contrastes en la distribución, creando zonas que cuentan con todas las facilidades en

ACE, 14 (42) CC BY-ND 3.0 ES | UPC Barcelona, España | La fragmentación socioespacial de las urbanizaciones populares 
colindancia con zonas que carecen de lo más básico. La delimitación entre fraccionamientos también genera «la singularización» de sectores (Vidal, 1997), enfatiza las diferencias y agudiza la segregación social y fragmentación urbana. La lejanía y la insularidad de los nuevos desarrollos también promueven la exclusión social y fomentan la exclusividad, la privatización y el repliegue de la convivencia (Rodríguez, 2006).

Hasta finales de los noventa, la expansión de las ciudades latinoamericanas se había dado en gran medida con base en urbanizaciones populares que se desarrollaban en la periferia. Ahí se localizaban los habitantes de escasos recursos, en zonas desfavorecidas, con carencia de equipamiento y en situación irregular respecto a la tenencia de la tierra. Hoy día, las transformaciones urbanas muestran un aumento en la discontinuidad de la traza urbana, por lo que puede apreciarse a simple vista la fragmentación de las ciudades. Si bien en las periferias de las ciudades las urbanizaciones populares permanecen, también proliferan los fraccionamientos en todas sus modalidades, donde se ha instalado la población de diferentes clases socio-económicas (Cerasoli, 2010).

A los habitantes de las urbanizaciones populares les afecta la desigualdad, ya que no disfrutan ampliamente de los beneficios y oportunidades que ofrece la ciudad; su marginalización les impide disfrutar de su entorno, ya que cada vez más está ocupado por fraccionamientos cerrados, dirigidos a una población de nivel socioeconómico medio y alto, que les dan la espalda. En la periferia también han proliferado las plazas comerciales, a las cuales los habitantes de las urbanizaciones populares tampoco pueden acceder, ya que estos comercios ideados para los grupos poblacionales de mayores ingresos les restringen el acceso. Si bien no necesariamente es explícita, sí lo es por otros medios; uno de ellos es que solo es posible acceder si se cuenta con auto, ya que no hay rutas de transporte público.

El importante cambio de algunos rasgos del patrón morfológico de las ciudades en este siglo resulta más evidente en las grandes metrópolis, pero la fragmentación socioespacial que las caracteriza también puede observarse en las ciudades medias e intermedias. La fragmentación impide la integración social y conduce a una ausencia de identidad de los habitantes con su entorno; contribuye al surgimiento de una ciudad atomizada que se asocia a estilos culturales de la transgresión, pero también a la exclusión provocada, entre otras cosas, por los mercados de la tierra y propiedades orientados al diseño y planeación que regulan y racionalizan la producción del espacio para imponer un orden concreto; es decir, el gobierno decide cómo funcionará el espacio según sus políticas públicas (Díaz, 2006; en Alvarado y Stringher, 2011). En este caso, las políticas públicas están orientadas a facilitar la intervención del sector privado para incrementar sus ganancias, sin «hacer ciudad».

El objetivo de este trabajo es mostrar las particularidades de la fragmentación socioespacial de las urbanizaciones populares de la periferia como unidad poblacional predominante en la ciudad intermedia de Culiacán Rosales. El estudio parte de la clasificación de las unidades poblaciones por nivel socioeconómico (residencial, medio y popular) para determinar el porcentaje de ocupación de las urbanizaciones populares, establecer una caracterización tipológica y analizar la distribución y los elementos divisorios. A partir de la georreferenciación, se analizaron los datos de las unidades poblacionales con la finalidad de hacer lecturas más complejas de los procesos espaciales, complementando con observación directa en campo y el análisis de imágenes del sitio.

Como lo documentan otros estudios (Hidalgo, Borsdorf, y Sánchez, 2007; Janoschka, 2002; Svampa, 2004; Tecco y Valdés, 2006; Valdés y Koch, 2009), puede apreciarse la proliferación de fraccionamientos cerrados y plazas comerciales localizadas junto a las urbanizaciones populares que impactan la forma de vida de sus habitantes. En Culiacán, las urbanizaciones populares siguen dominando la periferia, con la particularidad de que incluso entre ellas se buscan formas de

ACE, 14 (42) CC BY-ND 3.0 ES | UPC Barcelona, España | La fragmentación socioespacial de las urbanizaciones populares 3 en la periferia de la ciudad de Culiacán Rosales. DOI: http://dx.doi.org/10.5821/ace.14.42.8521 
diferenciación socioespacial. Después de esta introducción, el resto del trabajo se organiza en cinco secciones. En la segunda se aborda el sustento teórico de la investigación en relación con los conceptos fragmentación urbana y urbanizaciones populares. En la tercera se describe la metodología empleada. En la cuarta se caracteriza al caso de estudio. En la quinta sección se analiza la fragmentación urbana en las urbanizaciones populares y, finalmente, se presentan las conclusiones.

\section{La fragmentación urbana y las urbanizaciones populares}

\subsection{La fragmentación urbana}

Para autores como Sassen (1996), Mollenkopf y Castells (1991), la nueva morfología urbana puede entenderse a partir de la ciudad dual, desarrollada como resultado de la globalización, y esta también sirve de base para explicar la fragmentación de las ciudades. Sin embargo, las ciudades latinoamericanas desde finales de los noventa se expanden de manera insular, en donde conviven los centros comerciales con las urbanizaciones cerradas y con las urbanizaciones populares. Hoy es un rasgo de la morfología urbana que se ha generalizado. La clave de estos cambios es que enfatizan la separación entre grupos sociales, y las fronteras entre las múltiples urbanizaciones no solo separan a pobres y a ricos, sino que «separan a pobres de los menos pobres». De ahí que sea más objetivo comprender la ciudad latinoamericana como una ciudad fragmentada que como una ciudad dual en que domina el análisis dicotómico del centro y la periferia (Prévôt, 2001).

La mezcla del acelerado incremento poblacional, el clientelismo político y la falta de políticas públicas adecuadas de la última mitad del siglo XX, después en México promovieron la rápida conformación de colonias populares irregulares y un crecimiento disperso y de baja densidad, que a lo largo de los años se ha estado integrando a las ciudades y se ha densificado. Posteriormente, a partir de los noventa, en la expansión urbana han prevalecido los fraccionamientos cerrados, propiciadores de importantes impactos urbanos. En especial, la invasión de la clase media y alta en zonas habitacionales que tradicionalmente habían sido ocupadas por asentamientos populares condujo a la intensificación de las desigualdades sociales (Prévot, 2000; Thuillier, 2001). Así es que hoy, en la periferia de las ciudades en América Latina, los fraccionamientos cerrados están contiguos a asentamientos populares (Pérez, Gil y Bayona, 2017).

A pesar de que alrededor de las áreas poblacionales más desfavorecidas de la ciudad, colindantes con fraccionamientos cerrados, tengan un mejor entorno urbano, establecimientos de abastecimiento más cercanos, puedan trabajar más cerca prestando servicios domésticos, etc., a las nuevas familias, aun así predomina la desconfianza y el rechazo entre las diferentes unidades poblacionales (Roldán y Pérez, 2018). Este fenómeno está considerado por algunos autores como un signo de fragmentación del área urbana y de desintegración social (Thuillier, 2001; Sabatini, Cáceres y Cerda, 2001; Prévot, 2000). En gran medida, la cercanía espacial de áreas residenciales de diferentes niveles socioeconómicos, en lugar de propiciar mayor integración, vuelve más evidente la separación social de sus habitantes (Prévot, 2000).

Pero es importante aclarar que estos sistemas no solo son empleados por las personas de mayores ingresos para separarse de los de menores ingresos. Este sistema también lo emplean los habitantes de escasos recursos económicos (Rodríguez, 2018). La fragmentación actual consiste no solo en que hay una discontinuidad de la trama urbana de las nuevos fraccionamientos cerrados, de las plazas comerciales y las áreas productivas, con su entorno y con la ciudad, sino que las fronteras impuestas son «marcadamente discriminantes» (Link, 2008). Los muros y cerramientos de estas partes de la ciudad son un indicador objetivo del tipo de fragmentación de las ciudades (Gómez y Alvarado, 2016).

ACE, 14 (42) CC BY-ND 3.0 ES | UPC Barcelona, España | La fragmentación socioespacial de las urbanizaciones populares 
El término fragmentación en el ámbito urbano refiere las «lógicas de separación» que presentan las ciudades; también es empleado para referirse a los "procesos que hicieron estallar la unidad de la ciudad” (Prévôt, 2001, pp.35-41), quedando así las ciudades integradas por fragmentos, con características diferentes del resto, complicando su integración. Prévôt (2001) asocia el fenómeno de fragmentación urbana con componentes espaciales, dimensiones sociales y políticas, que se desarrollan en las ciudades, lógicas de separación y nuevas fronteras urbanas. Borsdorf (2003) menciona el surgimiento de nuevas formas de separación de funciones y elementos socioespaciales, ya no como antes, en una escala amplia (ciudad rica/ciudad pobre, zona habitacional/zona industrial), sino en una escala menor, en donde puede verse la cercanía geográfica de zonas habitacionales de diferentes niveles económicos dispuestas de manera insular, con muros que impiden la relación fluida entre los habitantes de los fraccionamientos y quienes viven fuera de ellos.

\subsection{La dimensión socioespacial de la fragmentación}

La idea de la dimensión socioespacial de la fragmentación es que una sociedad en archipiélago produce un entrelazamiento de diferentes espacios y otorga una visibilidad acrecentada de las diferencias, generado repliegues de todo tipo.

"La noción expresa una disociación social de las partes en relación con el conjunto urbano, una ruptura que puede llegar a la autonomía total, una fragmentación de la sociedad urbana como unidad y su reemplazo por una serie de territorios marcadamente identificados." (Navez-Bouchanine, 2001; en Prévôt, 2001, p. 40).

Retomando la explicación de Guzmán y Hernández (2013) sobre el aspecto social y el aspecto espacial de la fragmentación urbana, ellos explican que las diferencias sociales siempre han existido a lo largo de la historia. Consiste en la identificación de grupos o individuos en la estructura social establecida, diferenciados entre ellos mediante pautas económicas, culturales y educativas, desarrollando características particulares delimitadas por el espacio que ocupan, lo que los distingue de los demás. Esas particularidades desarrolladas por cada grupo los hace diferentes entre sí y esto genera tensiones, recurriendo al espacio como una herramienta de identificación social, iniciándose el proceso de fragmentación.

Por lo que toca al aspecto social, se van formando grupos que se identifican entre sí por lazos sociales, económicos o culturales, reforzados con el tiempo por la interacción entre los miembros del grupo, generando así una comunidad. El aspecto espacial inicia con la conformación de comunidad. Esta comunidad puede caracterizarse por tratarse de un grupo de varios hogares, personas con origen común, comunidades de vecinos, un barrio o cualquier otra división urbana local, que logran transformar el espacio en un lugar a su imagen y, semejanza.

Rossi (1999), a su vez, señala que cuando un grupo se concentra en un espacio lo transforma, pero también hay aspectos del espacio resistentes al cambio, por lo que los grupos se adaptan o repliegan, generando una identificación social y espacial del grupo, lo que hace que se diferencien de otros grupos y se desarrollen tensiones al defender la identidad y el territorio.

Las formas extremas y simétricas del proceso socioespacial son la producción de territorios residenciales afines, por un lado, y los barrios pobres, por otro. Para disminuir los contrastes entre ricos y pobres, se optó por una estrategia consistente en disminuir poco a poco las diferencias entre los dos extremos, lo que produjo una gran gama de grupos poblacionales diferentes en gradación, que en la práctica avivan las diferencias entre los barrios, entre las manzanas, estableciéndose nuevas fronteras entre ricos y pobres y también entre los pobres y los menos pobres. De modo que la pobreza ya no puede pensarse en términos de enclaves, sino de gradación (Prévôt, 2001).

ACE, 14 (42) CC BY-ND 3.0 ES | UPC Barcelona, España | La fragmentación socioespacial de las urbanizaciones populares 5 en la periferia de la ciudad de Culiacán Rosales. DOI: http://dx.doi.org/10.5821/ace.14.42.8521 


\subsection{Urbanizaciones populares}

La urbanización popular remite a la autoproducción y autogestión de viviendas por la población con ingresos insuficientes para adquirir una vivienda en el mercado formal. Partiendo de un enfoque más amplio, el término no solo incluye la producción de viviendas y asentamientos nuevos de nivel socioeconómico bajo, sino también la adecuación que hacen los habitantes en situación de pobreza de cualquier espacio en donde habiten. Este sentido amplio de la urbanización popular coincide con lo que plantean varios autores acerca de la construcción o adecuación social de un territorio. Se trata de un "proceso de domesticación del territorio" (Giglia, 2014, pp.79-80). Sin embargo, las urbanizaciones populares no son todas iguales; pueden clasificarse en pueblos, barrios, vecindades y unidades habitacionales con viviendas unifamiliares y con departamentos, colonias populares sobre suelo adquirido de manera formal o informal (Jiménez, 2016; ver también Connoly, 2005).

Los pueblos son urbanizaciones populares que surgieron antes y después de la llegada de los españoles. El patrón urbano inicial era la ubicación de los españoles al centro y en la periferia los pueblos preexistentes y los que construyeron los españoles. Cuando la ciudad se expandió, alcanzó a los pueblos y posteriormente los rebasó; perdieron su categoría de pueblos y se convirtieron en barrios. Los nuevos barrios fueron la unidad mediante la cual creció la ciudad, dirigidos a todos los sectores de la sociedad, pero homogéneos en su interior.

Hoy día, los barrios y pueblos siguen acogiendo a los pobladores de escasos recursos en viviendas autoproducidas. A los barrios, como unidades de integración y expansión de la ciudad de siglos pasados, se les sumaron en el siglo XX nuevas estructuras: los fraccionamientos populares formales, las urbanizaciones populares (conocidas en México como colonias populares), los conjuntos habitacionales y los fraccionamientos de interés social, producidas formalmente. Estos tipos de estructuras territoriales y sociales tienen dinámicas propias.

Los fraccionamientos populares formales consisten en la oferta formal de lotes a precios accesibles. Esta modalidad inició, en Guadalajara, a principios del siglo XX, en donde los fraccionadores eran los intermediarios entre los propietarios de las tierras y los compradores. La población compraba los lotes sin servicios a precios accesibles, con créditos privados, sin pagar intereses, generalmente sin enganche (Jiménez, 2016).

Las colonias populares de origen informal son la estructura más dominante y persistente de las ciudades mexicanas, autogestionadas y autoproducidas por la población. Surgieron a mediados del siglo pasado y por ello muchas de ellas ya se encuentran en áreas hoy centrales de la ciudad; son áreas consolidadas y una cantidad importante ha sido legalizada. Otras colonias populares se hallan en la orilla de las ciudades y otras más alejadas. Aquí es en donde habita la mayoría de las personas de escasos recursos.

Los conjuntos habitacionales surgieron a partir de los sesenta. Esta modalidad de alojamiento contaba con financiamiento del Estado, aunque también, en algunos casos, provino de la iniciativa privada que los desarrolló. Fueron construidos para trabajadores asalariados y con seguridad social. Los fraccionamientos de interés social son la modalidad más reciente; su construcción inició a finales de los noventa. Se construyeron en la periferia de la ciudad, ocupan grandes extensiones de tierra, muchos de ellos siguen un modelo insular y cerrado, con un uso inicialmente monofuncional, que se va transformando con el tiempo. Cabe mencionar que no todos estos tipos de urbanización popular se encuentran en todas las ciudades mexicanas.

ACE, 14 (42) CC BY-ND 3.0 ES | UPC Barcelona, España | La fragmentación socioespacial de las urbanizaciones populares 6 en la periferia de la ciudad de Culiacán Rosales. DOI: http://dx.doi.org/10.5821/ace.14.42.8521 


\section{Metodología}

El tipo de investigación es descriptiva con alcance correlacional. La investigación toma como caso de estudio a la ciudad de Culiacán Rosales, con un enfoque mixto. Las fuentes de información para los datos cuantitativos fueron información cartográfica y censal, proporcionada principalmente por el Instituto Municipal de Planeación (IMPLAN), por la Dirección de Asuntos Jurídicos del Ayuntamiento de Culiacán y la Comisión para la Regularización de la Tenencia de la Tierra (CORETT, hoy Instituto Nacional de Suelo Sustentable, INSUS), Instituto Nacional de Estadística y Geografía (INEGI) y el Reglamento de Construcción del Municipio de Culiacán 2007. Los datos cualitativos se obtuvieron por medio de observación directa en visitas de campo y revisión del plano de la ciudad con Google Earth.

En el estado de la cuestión se hace una revisión teórica para definir los conceptos fragmentación urbana y urbanizaciones populares, conceptos clave en la investigación. La parte empírica se desarrolla con las técnicas de investigación de elaboración de mapas temáticos georreferenciados empleando el software QGIS, observación directa y análisis de imágenes obtenidas en visitas de campo y satelitales empleando el software Google Earth y se desarrolla en cuatro métodos.

Método 1. El caso de estudio. Primero se procedió a la contextualización del caso de estudio para determinar la superficie ocupada de acuerdo con el tipo de unidad poblacional en la ciudad de Culiacán Rosales, procediendo a clasificar las unidades poblacionales por nivel socioeconómico: (1) urbanizaciones populares, (2) urbanizaciones de nivel medio, y (3) urbanizaciones de nivel residencial. Para analizar la expansión de la ciudad de Culiacán Rosales por tipos de unidades poblacionales, se revisó la información cartográfica de unidades poblacionales proporcionada por el (IMPLAN, 2018), encontrando las unidades poblacionales clasificadas en campestres, colonias, fraccionamientos, irregulares, poblados y secciones. Para determinar qué unidades poblacionales pertenecían a cada grupo (urbanización popular, nivel medio y nivel residencial), se tomaron en consideración varias características; una de ellas fue:

1. Recurrir al Reglamento de Construcción del Municipio de Culiacán (RCMC, 2007), en el título octavo, artículo 253, correspondiente a fraccionamientos, donde los clasifica respecto a los usos de suelo. Se encontraron los fraccionamientos de uso habitacional en la primera denominación. En el artículo 254 establece que los fraccionamientos para uso habitacional son aquellos en los que sus lotes se destinan a edificar vivienda, los cuales pueden ser: (I) vivienda de objetivo social, (II) vivienda de interés social, (III) vivienda popular, (IV) vivienda con servicios progresivos, (V) vivienda media, (VI) vivienda residencial, y (VII) vivienda campestre.

Las urbanizaciones populares son:

I. Vivienda de objetivo social.

II. Vivienda de interés social.

III. Vivienda popular.

IV. Vivienda con servicios progresivos.

Las urbanizaciones de vivienda media son:

V. Vivienda media; debe tener un frente mínimo de ocho metros.

Las urbanizaciones de vivienda residencial:

VI. $\quad$ Vivienda residencial; debe tener un frente mínimo de 12 metros.

VII. Vivienda campestre; el lote debe tener una superficie mínima de mil metros cuadrados.

ACE, 14 (42) CC BY-ND 3.0 ES | UPC Barcelona, España | La fragmentación socioespacial de las urbanizaciones populares 
2. Se analizaron las características de las viviendas particulares habitadas y de la población, información proporcionada por el (INEGI, 2015). Esas características corresponden a vivienda con recubrimiento en piso, energía eléctrica, agua entubada, drenaje y número de habitantes por cuarto a nivel de manzana. Y de las características de la población se retomó el promedio de escolaridad.

3. Se consideraron las características de la vivienda, mediante la observación en visitas de campo y con la herramienta de Google Earth, para identificar la autoproducción, ya que el término urbanización popular no solo incluye la producción de viviendas y asentamientos nuevos, sino también la adecuación y autoproducción que hacen los habitantes en situación de pobreza de cualquier espacio en donde habiten (Giglia, 2014; Jiménez, 2016). Retomando la metodología empleada por Baragona (2019), quien emplea las imágenes de mapas satelitales para identificar la pobreza extrema.

Método 2. Tipificación de urbanizaciones populares. Respecto al método anterior, donde se buscó identificar las urbanizaciones populares y con base en la bibliografía se logró identificar una gran diversidad de unidades poblacionales consideradas urbanizaciones populares, como las colonias populares -algunas de origen formal, otras de origen informal ya regularizadas-, los fraccionamientos populares de diversos tipos, asentamientos irregulares que no cuentan con título de propiedad y en casos más particulares de viviendas en pueblos y barrios. Se procedió a hacer una tipificación de acuerdo con la situación legal, organizándolas en tres grupos principales, quedando las urbanizaciones populares como formales, informales y poblados. Esas clasificaciones son descritas en el apartado correspondiente y, a su vez, se mencionan las urbanizaciones populares de cada grupo representado en una tabla.

Método 3. Urbanizaciones populares en la ciudad de Culiacán Rosales. De acuerdo con el método 2, se obtuvo el porcentaje de las urbanizaciones populares respecto al resto de unidades poblacionales. Dicha cifra fue obtenida de las unidades poblacionales proporcionadas por el (IMPLAN, 2018), en donde nos dimos cuenta de que no aparecía una gran cantidad de asentamientos en situación de irregularidad. Por ese motivo, fue necesario recurrir al INSUS; ahí solo se logró obtener información de colonias que iniciaron en situación de irregular, pero ya se encuentran regularizados. Posteriormente, se recurrió a la Dirección de Asuntos Jurídicos, del Ayuntamiento de Culiacán; su personal encargado de procesos de regularización (Lic. Meza) cuenta con información referida al total de asentamientos irregulares; además, tiene conocimiento de la ubicación, nombre, tamaño y número de lotes, por lo que nos apoyó con la localización en el mapa para la georreferenciación. Por medio de la integración de los polígonos de las urbanizaciones populares en situación de irregularidad faltantes, se logró obtener una cifra más aproximada.

Método 4. Urbanizaciones populares fragmentadas. Para analizar la fragmentación socioespacial de las urbanizaciones populares en la periferia de la ciudad, primero se procedió a representar los índices de marginación y pobreza mediante un plano georreferenciado (PMDUC, 2014). Posteriormente, se hizo un plano en el que se representan las tipologías de urbanizaciones populares dispersas por la periferia. Se halló gran coincidencia entre los índices más altos de marginación y pobreza y la localización de las urbanizaciones populares. Finalmente, se hizo una representación de los elementos divisorios en los tipos de urbanizaciones populares usados para delimitar una urbanización de otras. Para ello, se tomó como base la representación fotográfica obtenida en visitas de campo. Se consideró un caso en particular de los diferentes tipos de urbanizaciones populares, determinando un ejemplo de cada caso (fraccionamiento popular con asentamiento irregular, fraccionamiento popular con poblados, fraccionamiento popular con colonia popular, fraccionamiento popular con fraccionamiento popular, fraccionamientos populares con espacios intersticiales y entre fraccionamientos populares cerrados).

ACE, 14 (42) CC BY-ND 3.0 ES | UPC Barcelona, España | La fragmentación socioespacial de las urbanizaciones populares 8 en la periferia de la ciudad de Culiacán Rosales. DOI: http://dx.doi.org/10.5821/ace.14.42.8521 


\section{Análisis del caso de Culiacán Rosales}

\subsection{Contextualización del caso de estudio}

El caso de estudio es la ciudad de Culiacán Rosales localizada en el municipio de Culiacán, en la región centro del estado de Sinaloa, al noroeste de México, capital del estado desde 1873. Es una ciudad intermedia (SUN, 2018) con 858 mil 639 habitantes y una superficie de 242.2 km² (INEGI, 2015). Por tamaño y por tratarse de la capital estatal, se le declaró zona metropolitana (DZMM, 2015). La Tabla 1 contiene la relación de población por décadas, a excepción del último periodo, logrando observar que la población de 1980 casi se duplicó respecto a la década anterior; otro crecimiento considerable se observa para el 2015 aun tratándose de un periodo de cinco años.

Tabla 1. Población de la ciudad de Culiacán Rosales

\begin{tabular}{|l|l|l|l|l|l|l|}
\hline & 1970 & 1980 & 1990 & 2000 & 2010 & 2015 \\
\hline Población CCR & 167.956 & 304.826 & 415.046 & 540.823 & 675.773 & 858.639 \\
\hline
\end{tabular}

Nota: $C C R=$ Ciudad de Culiacán Rosales. ZMC=Zona Metropolitana de Culiacán. Fuente: Instituto Nacional de Estadística y Geografía (2015).

La ciudad de Culiacán Rosales ha sido analizada en varias ocasiones por diversos investigadores respecto a temas de segregación, división social del espacio y fragmentación (Acosta, 2018; Acosta y Marmolejo, 2016; Pérez et al., 2017; Rodríguez, 2006, 2018; Roldán y Pérez, 2018). Los análisis iniciaron desde 1970, pero fue hasta 1990 en que la segregación se intensificó, haciendo eco de este rasgo característico de las grandes ciudades latinoamericanas. Debido al rápido crecimiento demográfico y urbano de Culiacán Rosales, se prevé que en pocos años pase a la lista de ciudades grandes. De lo anterior surge la importancia de analizar esta ciudad intermedia, con la finalidad de visualizar sus conflictos y que se van agravando según se expande. En ninguno de los casos de investigaciones anteriores se ha analizado la fragmentación urbana exclusivamente en las urbanizaciones populares, como las que se analizan en el presente artículo.

\subsection{Expansión de Culiacán Rosales por tipos de unidad poblacional}

Con los datos sobre las unidades poblacionales proporcionados por el IMPLAN (2018), se encontró la siguiente clasificación: campestres, colonias, fraccionamientos, irregulares, poblados y secciones. ${ }^{1} \mathrm{El}$ IMPLAN no diferencia los niveles socioeconómicos de las unidades poblacionales. Sin embargo, en la clasificación proporcionada puede determinarse que los asentamientos campestres son de nivel residencial, los asentamientos irregulares y poblados son catalogados como urbanizaciones populares, pero dentro de las colonias, fraccionamientos y secciones, se pueden encontrar vivienda de nivel medio y residencial, así como vivienda popular.

Para distinguir cuáles son colonia y fraccionamientos populares, se recurrió en primer lugar al Reglamento de Construcción del Municipio de Culiacán (RCMC, 2007), título octavo, capítulos I y II, en los que se establecen las características de las dimensiones de los frentes de lotes y costos de la vivienda. Luego, se analizaron las características de las viviendas habitadas considerando si cuentan con recubrimiento en piso, energía eléctrica, agua entubada, drenaje, número de habitantes por cuarto, y de la población se tomó en cuenta el nivel escolar (INEGI, 2015), además de considerar las características de la vivienda como la autoconstrucción, mediante la observación en visitas de campo

\footnotetext{
1 Se llama secciones a los nuevos desarrollos habitacionales que ocupan terrenos vacantes en una colonia o cuando un fraccionamiento se desarrolla en partes o por secciones; por tanto, es una modalidad de fraccionamiento que alude a la etapa de construcción.
}

ACE, 14 (42) CC BY-ND 3.0 ES | UPC Barcelona, España | La fragmentación socioespacial de las urbanizaciones populares 9 en la periferia de la ciudad de Culiacán Rosales. DOI: http://dx.doi.org/10.5821/ace.14.42.8521 
y con la visualización en Gogole Earth. La superficie correspondiente a cada unidad poblacional por nivel socioeconómico (popular, medio y residencial) se aprecia en la tabla 2, incluyéndose datos de equipamiento urbano para complementar la sumatoria del crecimiento por décadas.

Las urbanizaciones populares se han mantenido en los índices superiores de superficie ocupada en la mayor parte de las décadas. En el periodo 1971-1980 estas constituían el 79 por ciento. En los dos periodos siguientes se registra la mayor expansión en la ciudad. La cifra alcanza a duplicarse respecto a la anterior. En ambos periodos, las urbanizaciones populares también constituyen la mayoría, contribuyendo con el 63\% del crecimiento en el periodo 1981-1990, y con 53\% en 1991-2000. Para el año 2010 estas conformaban el 53\% de la superficie de la ciudad.

En el último periodo las urbanizaciones populares disminuyen, pasando a segundo lugar; son rebasadas por el nivel medio. Esto podría obedecer a una mayor demanda de vivienda de nivel medio de la población y a gestiones para evitar los asentamientos irregulares, además de considerar que este periodo cuenta con dos años menos que los anteriores. (Tabla 2.)

Tabla 2. Crecimiento por periodos de las unidades poblacionales

\begin{tabular}{|l|r|r|r|r|r|r|r|r|r|r|}
\hline U.P. & 1940 & $\begin{array}{c}1941- \\
1950\end{array}$ & $\begin{array}{c}1951- \\
1960\end{array}$ & $\begin{array}{c}1961- \\
1970\end{array}$ & $\begin{array}{c}1971- \\
1980\end{array}$ & $\begin{array}{c}1981- \\
1990\end{array}$ & $\begin{array}{r}1991- \\
2000\end{array}$ & $\begin{array}{c}2001- \\
2010\end{array}$ & $\begin{array}{c}\text { 2011- } \\
2018\end{array}$ & $\begin{array}{c}\text { Total x } \\
\text { UP }\end{array}$ \\
\hline U. Populares & 580.20 & 661.46 & 160.34 & 1173.33 & 858.45 & 1485.16 & 2209.98 & 1233.06 & 371.71 & 8733.69 \\
\hline Medio & 200.13 & 23.79 & & 233.43 & 122.58 & 321.95 & 142.98 & 465.93 & 506.09 & 2016.88 \\
\hline Residencial & 145.15 & & & & & 74.26 & 1385.35 & 398.90 & 227.74 & 2231.39 \\
\hline Equipamiento & 305.30 & & 5.63 & 503.68 & 102.69 & 458.06 & 400.32 & 223.51 & 76.15 & 2075.34 \\
\hline Total periodo & 1230.78 & 685.25 & 165.97 & 1910.44 & 1083.72 & 2339.43 & 4138.63 & 2321.40 & 1181.69 & 15057.30 \\
\hline
\end{tabular}

Nota: U.P.=Unidad Poblacional; U. Populares=Urbanizaciones Populares. Las superficies se expresan en hectáreas. Fuente: Información del Instituto Municipal de Planeación (IMPLAN). Colonias 2018. Manipulado por Belén P.P.

El tipo de urbanización popular que predominaba en los primeros años de conformación de la ciudad fue el de los barrios. Cuando inició el proceso de crecimiento acelerado de la ciudad en 1970 y otro periodo se da en 1990, algunos poblados fueron integrados la ciudad, convirtiéndose en colonias populares, considerando que antes de 2000 la expansión de la ciudad se dio principalmente por la formación de colonias populares y después de ese año la expansión de la ciudad se debió fundamentalmente a la construcción formal de fraccionamientos populares.

En este periodo, el crecimiento de los poblados se detuvo completamente, mientras que aumentó el de los asentamientos irregulares. Esto se debió principalmente a la disminución de oferta de suelo de precio accesible, ya que en este periodo solo se ofrecieron viviendas terminadas, adquiridas bajo un crédito hipotecario, en la gran parte de la población no contaba con acceso a un crédito.

En la Figura 1 cada imagen corresponde a un periodo representando el crecimiento que se integró, identificadas por el tipo de unidad poblacional de acuerdo con el nivel socioeconómico: residencial, medio y popular, considerando el centro fundacional como equipamiento desde el inicio, donde se observa que gran parte del área está ocupada por las urbanizaciones populares.

La dispersión se logra observar desde 1950, cuando aparecen los primeros asentamientos separados completamente del conjunto urbano, tendencia que continúa en cada periodo hasta el actual, al que se le suma la dispersión de acuerdo con el tipo de unidad poblacional, las cuales colindan entre sí y logran diferenciarse entre ellas; incluso, sucede con las diferentes tipologías que conforman las urbanizaciones populares.

ACE, 14. (42) CC BY-ND 3.0 ES | UPC Barcelona, España | La fragmentación socioespacial de las urbanizaciones populares 
Figura 1. Distribución por décadas de las unidades poblacionales
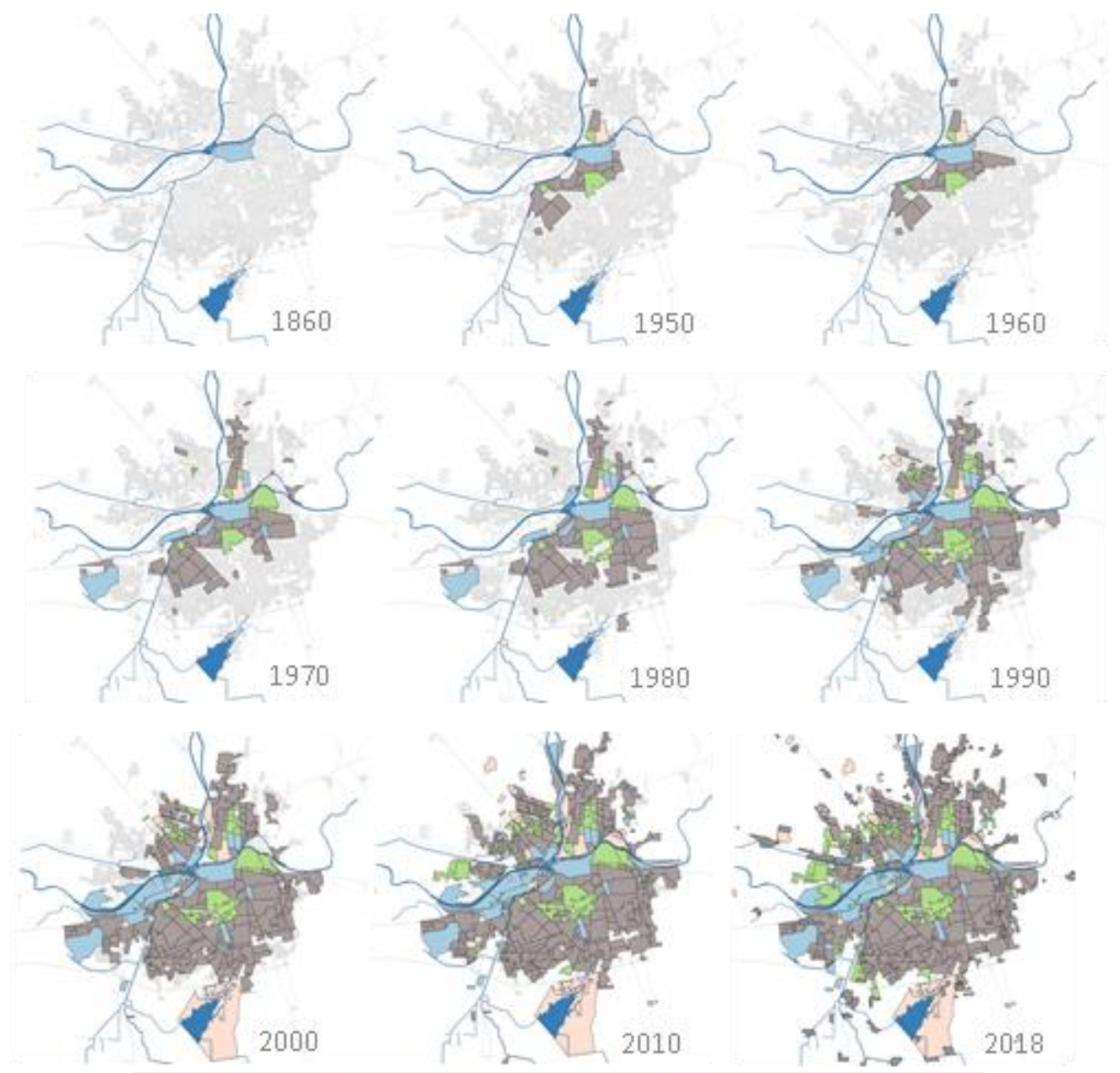

SIMBOLOGIA $\square$ EQUIPAMEINTO $\square$ POPULAR $\square$ MEDIO $\square$ RESIDENCIAL

Fuente: IMPLAN. Colonias 2018. Adaptación de Pérez, B.

\subsection{Tipificación de las urbanizaciones populares}

La definición de urbanización popular incluye tanto autoproducción como la gran variedad de modalidades habitacionales de producción de vivienda nueva, para la población de escasos recursos económicos, que financian los organismos públicos y privados. Así, las urbanizaciones populares incluyen tres principales tipos: las urbanizaciones populares formales, las informales y los poblados. Cada uno de estos grupos se constituye por diferentes tipos de urbanizaciones que forman subgrupos según sus características (ver otra clasificación reciente en Pinedo y Lora, 2016).

Las urbanizaciones populares formales son los asentamientos que cuentan con un título de propiedad, disponen de los servicios básicos, pagan impuestos y son legales ante las autoridades y, por tanto, están registrados. En este grupo se incluyen las colonias populares constituidas formalmente desde el inicio y aquellas que comenzaron de manera informal, pero que con el paso de los años lograron obtener un título de propiedad con base en programas de regularización.

ACE, 14 (42) CC BY-ND 3.0 ES | UPC Barcelona, España | La fragmentación socioespacial de las urbanizaciones populares 
También en este tipo aparecen los fraccionamientos populares en sus diferentes versiones, ya sean de objetivo social, interés social, popular y con servicios progresivos (RCMC, 2007). Todos ellos se caracterizan porque se construyen en serie por inmobiliarias y se financian principalmente por instituciones públicas como el Instituto del Fondo Nacional de la Vivienda para los Trabajadores (INFONAVIT), se comercializan viviendas terminadas o pies de casa y también se ofrecen en menor medida terrenos con servicios disponibles, que dejan la edificación de la vivienda en manos del propietario.

Las urbanizaciones populares informales, son aquellos en donde los lotes fueron vendidos sin contar con los requerimientos legales -conocidas comúnmente como asentamientos irregulares- se caracterizan por carecer de un título de propiedad. Los intermediarios entregan los lotes a los futuros propietarios a precios muy accesibles, debido a la falta de documentación legal, además de la carencia de servicios, infraestructura y equipamiento. También hay registros de venta de viviendas en secciones de fraccionamientos populares inconclusos, ya que algunas desarrolladoras inician las obras de urbanización de los terrenos recién adquiridos sin esperar la resolución de asuntos legales, como el cambio de usos de suelo y demás aspectos que pueden terminar en el rechazo de ejecución del desarrollo por las autoridades. En estos casos, las organizaciones -incluso las mismas desarrolladoras - venden esas viviendas a bajo costo por la carencia de documentación oficial «de terminación de obra» y dejan la problemática a los nuevos compradores.

El término de poblados se refiere a los asentamientos rurales sobre suelos ejidales, contiguos al área urbana. Debido a la expansión urbana, han sido alcanzados por la ciudad y en algunos casos rebasados, quedando inmersos en ella. Estos asentamientos se convierten posteriormente en barrios de la ciudad, una vez que han quedado completamente inmersos en ella. (Tabla 3.)

Tabla 3. Clasificación de urbanizaciones populares

\begin{tabular}{|l|l|}
\hline Grupos & Subgrupos \\
\hline Formales & $\begin{array}{l}\text { Colonias populares } \\
\text { - Origen formal } \\
\text { - Origen informal (ya regularizadas) } \\
\text { Fraccionamientos populares } \\
\text { - De vivienda de objetivo social, interés social, popular, servicios progresivos } \\
\text { (vecindades, conjuntos habitacionales horizontales y verticales, multifamiliares) } \\
\text { - Lotes (disponibles para la auto-construcción) }\end{array}$ \\
\hline Informales & $\begin{array}{l}\text { Asentamientos irregulares } \\
\text { - Ocupación de terrenos (agrícola, privado, público, de riesgo, reserva ecológica) } \\
\text { - Ocupación de vivienda (fraccionamientos sin concluir por problemas legales) }\end{array}$ \\
\hline Poblados & $\begin{array}{l}\text { Asentamientos rurales, comunidades y ejidos alcanzados por el área urbana } \\
\text { Barrios }\end{array}$ \\
\hline
\end{tabular}

Fuente: Elaborado propia.

\subsection{Urbanizaciones populares en Culiacán Rosales}

Dos terceras partes de la superficie habitacional de la ciudad de Culiacán Rosales están ocupadas por urbanizaciones populares. En la Tabla 4 aparece la relación de superficie y porcentaje de ocupación por tipo de unidad poblacional respecto al nivel socioeconómico, considerando las unidades poblacionales proporcionadas por el IMPLAN (2018). 
Tabla 4. Superficie de las unidades poblacionales de Culiacán Rosales

\begin{tabular}{|l|r|r|}
\hline Unidad poblacional & \multicolumn{1}{|l|}{ Hectáreas } & \multicolumn{1}{|l|}{ Porcentaje } \\
\hline Urbanizaciones populares & $8.650,44$ & $67,28 \%$ \\
\hline Medio & $2.016,88$ & $15,54 \%$ \\
\hline Residencial & $2.231,39$ & $17,19 \%$ \\
\hline Total & $12.981,96$ & $100,00 \%$ \\
\hline
\end{tabular}

Fuente: Elaboración propia, con base en información del Instituto Municipal de Planeación (IMPLAN). Colonias 2018.

Aunque debe especificarse que el total de asentamientos irregulares y poblados es aún mayor al registrado. Esto se debe a que el IMPLAN no cuenta con registro oficial de los asentamientos irregulares y rurales, unidades poblacionales que se suman a los asentamientos populares; solo tiene en consideración algunos cuantos del total que en verdad existen. La ausencia de información, de acuerdo con miembros del Ayuntamiento de Culiacán, obedece a la tradicional excusa de que sería una forma de brindar atención a un acto considerado ilegal. Sin embargo, en la Dirección de Asuntos Jurídicos del $\mathrm{H}$. Ayuntamiento de Culiacán opera personal encargado de monitorear los asentamientos de origen irregular. Mediante esta fuente se lograron cuantificar y localizar en un mapa dichos asentamientos. En la Tabla 5 se presenta una cifra más aproximada a la realidad, que incluye las hectáreas y el porcentaje correspondiente a las urbanizaciones que el IMPLAN no incluyó, incrementando a 9992.25 hectáreas, lo que representa el 70.17 por ciento de las urbanizaciones populares.

Tabla 5. Superficie rectificada de unidades poblacionales de Culiacán Rosales

\begin{tabular}{|l|r|r|}
\hline Unidad poblacional & \multicolumn{1}{|l|}{ Hectáreas } & \multicolumn{1}{|l|}{ Porcentaje } \\
\hline Urbanizaciones populares & $9.992,25$ & $70,17 \%$ \\
\hline Medio & $2.016,88$ & $14,16 \%$ \\
\hline Residencial & $2.231,29$ & $15,67 \%$ \\
\hline Total & $14.240,52$ & $100,00 \%$ \\
\hline
\end{tabular}

Fuente: Elaboración propia, con base en información del IMPLAN. Colonias 2018. H. Ayuntamiento de Culiacán, Dirección de Asuntos Jurídicos.

\section{Urbanizaciones populares fragmentadas}

\subsection{Fragmentación al interior de las urbanizaciones populares}

En la Figura 2 se muestra el índice socioeconómico de marginación y pobreza de la ciudad de Culiacán, estudio de la Facultad de Arquitectura de la UNAM (2014). El color más oscuro representa los índices más elevados de marginación y pobreza, los cuales se observan en la periferia de la ciudad. El color más claro indica los índices más bajos; esto se observa generalmente en las partes centrales de la ciudad en polígonos muy reducidos.

El índice más alto de marginación y pobreza solo persiste en la periferia de la ciudad, pero debe especificarse que este índice no es el único en la periferia; también se halla el índice alto, medio e incluso el muy bajo, aunque en menores cantidades, configurándose una periferia con múltiples niveles contiguos; las diferencias se ven acrecentadas, se genera un ambiente de desconfianza, desigualdades de acceso a los servicios y equipamiento de la ciudad y repliegues de grupos sociales.

ACE, 14 (42) CC BY-ND 3.0 ES | UPC Barcelona, España | La fragmentación socioespacial de las urbanizaciones populares 
Figura 2. Índice socioeconómico de marginación y pobreza

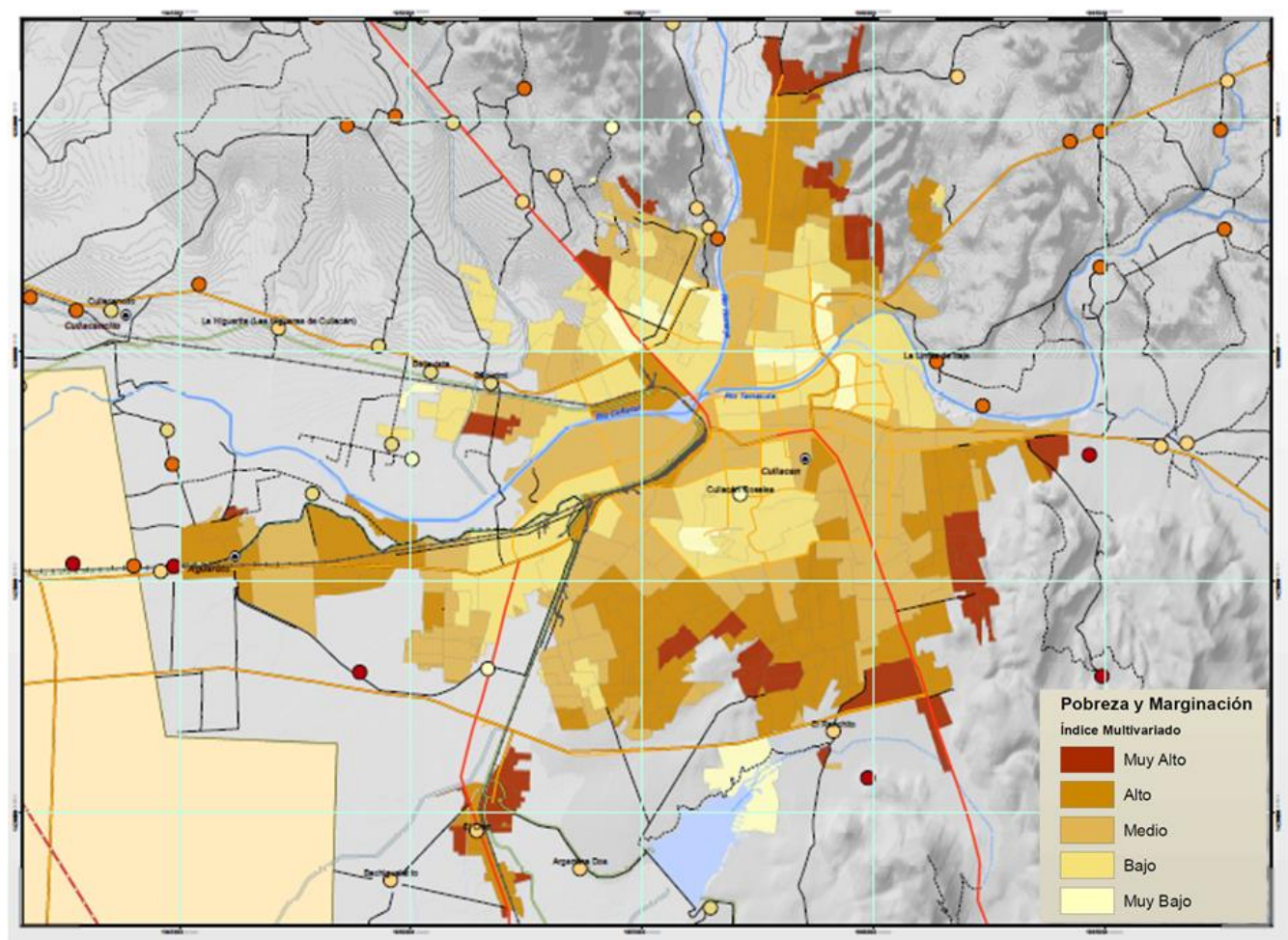

Fuente: IMPLAN (2018). Programa Municipal de Desarrollo Urbano de Culiacán, 2014. Elaborado por la Facultad de Arquitectura de la UNAM, agosto de 2014.

En la Figura 3 se aprecia el área ocupada por las urbanizaciones populares, en las diferentes tipologías que entran en el grupo, distribuidas por la ciudad. Se distingue que la ubicación de las urbanizaciones populares coincide con los niveles de marginación y pobreza (UNAM, 2014) catalogados como muy altos, altos y medios.

Además, se observa que gran parte de las colonias populares de la antigua periferia han pasado a un anillo interno debido a que la expansión de la ciudad las ha absorbido. Recientemente, los fraccionamientos populares, los asentamientos irregulares y los poblados también forman parte de la periferia, comparten un espacio y un nivel socioeconómico, pero no una integración, ya que cada grupo se diferencia y delimita de los demás.

Los habitantes de las urbanizaciones populares están limitados de los beneficios y oportunidades que ofrece la ciudad; tienden a ser relegados y excluidos. Los rasgos de la morfología reciente de las ciudades, que propicia la cercanía territorial de las urbanizaciones cerradas dirigidas a los sectores medios y altos limitan el acceso a su entorno inmediato a la población de las urbanizaciones populares. Sus habitantes ya no pueden disfrutar del entorno, pues el resto de las unidades habitacionales les da la espalda.

Además, la fragmentación de Culiacán Rosales también se da al interior de las urbanizaciones populares, entre las diferentes tipologías, sean fraccionamientos populares, colonias populares, asentamientos irregulares y poblados; se toman medidas para marcar una separación entre sí y cada asentamiento busca separarse de sus vecinos inmediatos. 
Figura 3. Urbanizaciones populares de la ciudad de Culiacán Rosales

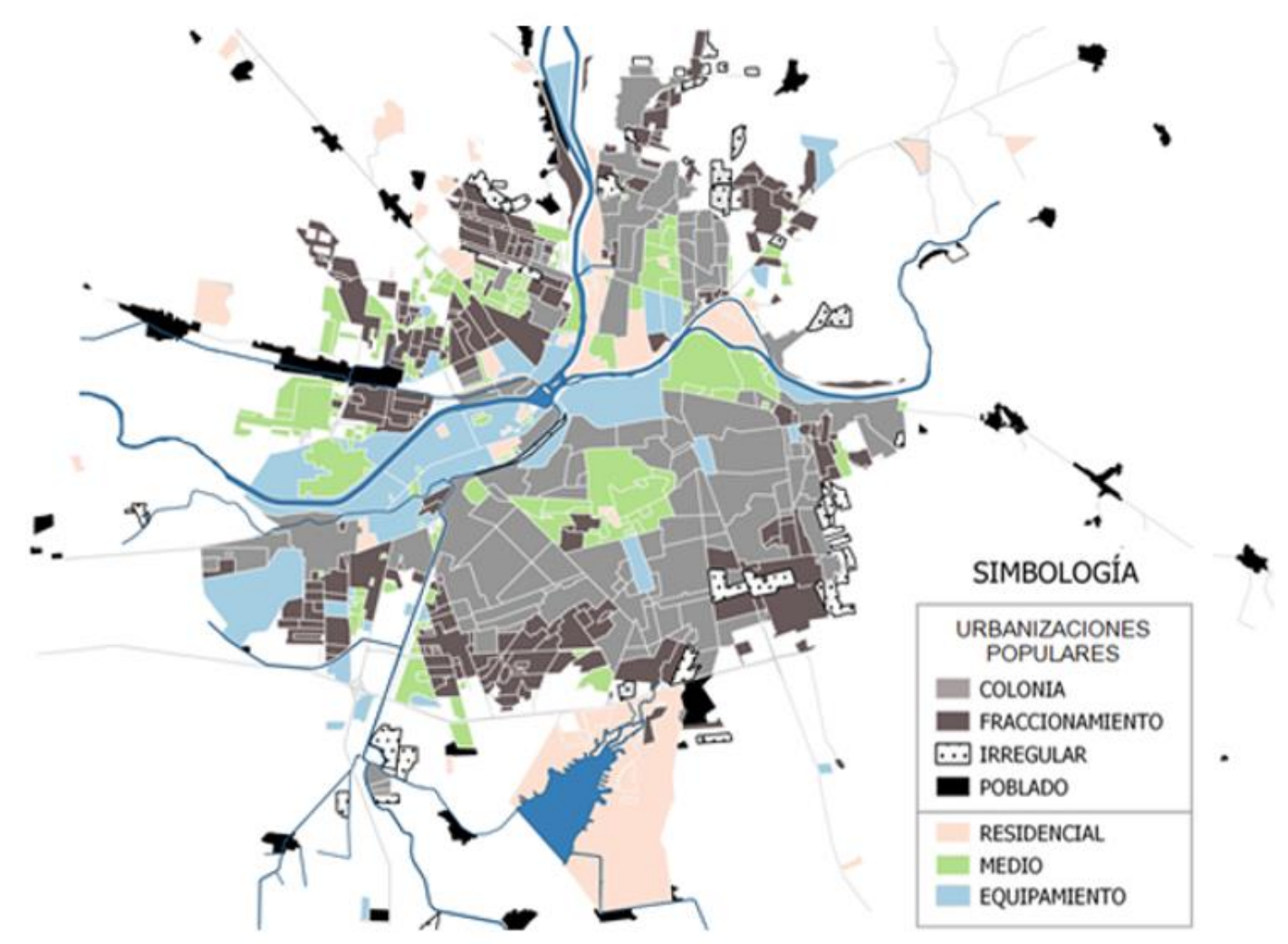

Fuente: Información del IMPLAN (2018). Colonias 2018. Manipulado por la autora.

\subsection{Casos particulares de urbanizaciones populares fragmentadas}

La presencia de elementos divisorios entre las urbanizaciones populares impide la continuidad de vialidades, les da la espalda a asentamientos en peores condiciones de precariedad, impide el libre tránsito y complica el acceso. Estos muros en algunos casos son colocados por la organización vecinal, o en algunos casos solo refuerzan los instalados por las mismas desarrolladoras, con el fin de mejorar las condiciones de comercialización de las viviendas.

En la Figura 4 se aprecia la presencia de muros para dividir la continuidad entre un fraccionamiento popular y un asentamiento irregular en la periferia de la ciudad.

La Figura 5, compuesta por dos imágenes, corresponde a un asentamiento rural, ya integrado al conjunto urbano; es atravesado por una vialidad que conecta la ciudad con otros asentamientos externos. En la imagen del inciso (a) se aprecia un acceso monumental a un fraccionamiento popular por dicha vialidad principal que conecta a la ciudad con el exterior, además de contar con delimitaciones perimetrales como canales y espacios intersticiales, lo que se aprecia en la imagen del inciso (b); dichos aspectos contribuyen a la delimitación y generan diferencias entre asentamientos. 
Figura 4. Presencia de muros entre un fraccionamiento popular y asentamiento irregular
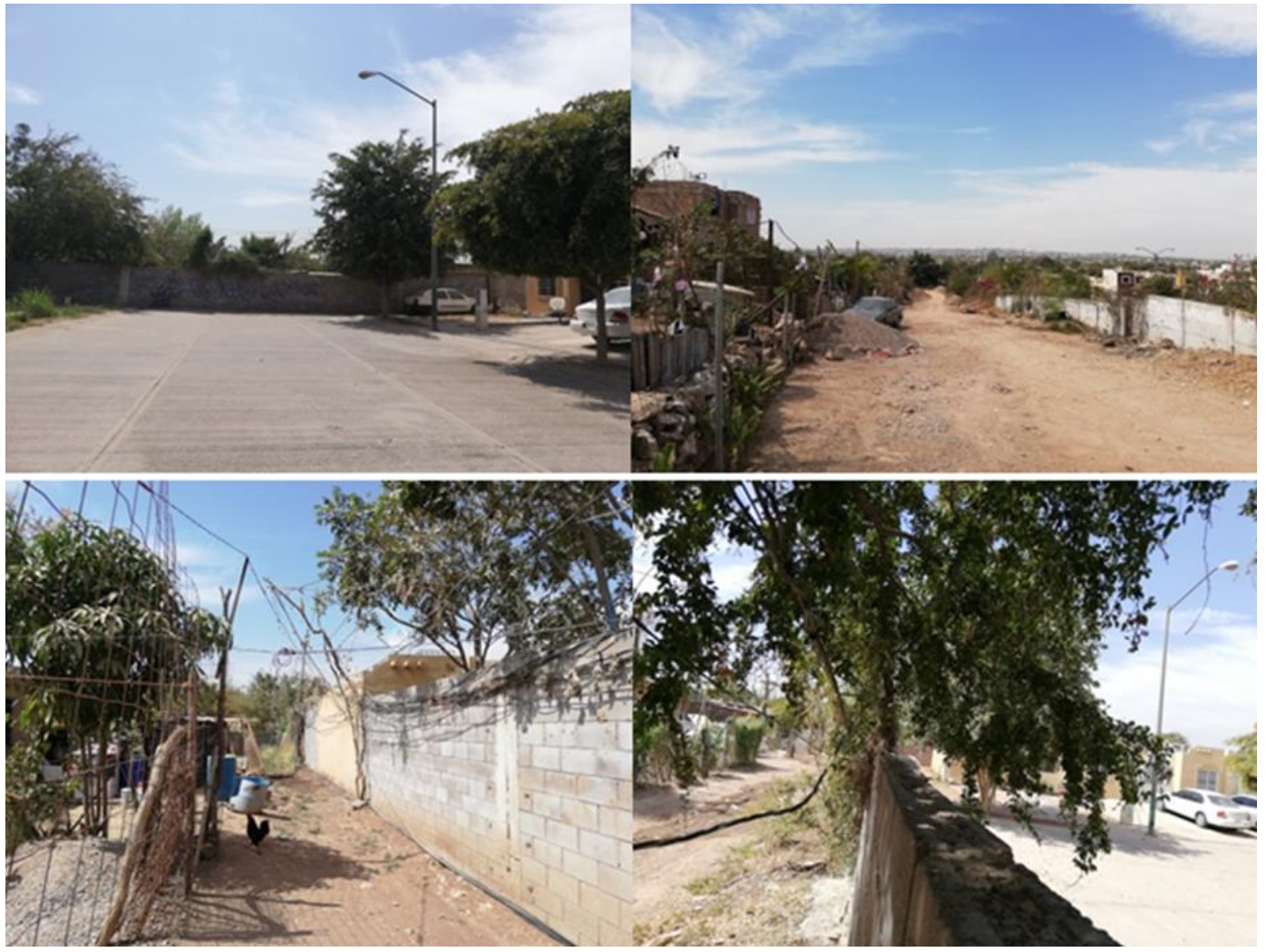

Fuente: Capturado por Belén P.P. Fraccionamiento Florenza y asentamiento irregular Antorcha Campesina.

Figura 5. Divisiones entre fraccionamiento popular y poblado

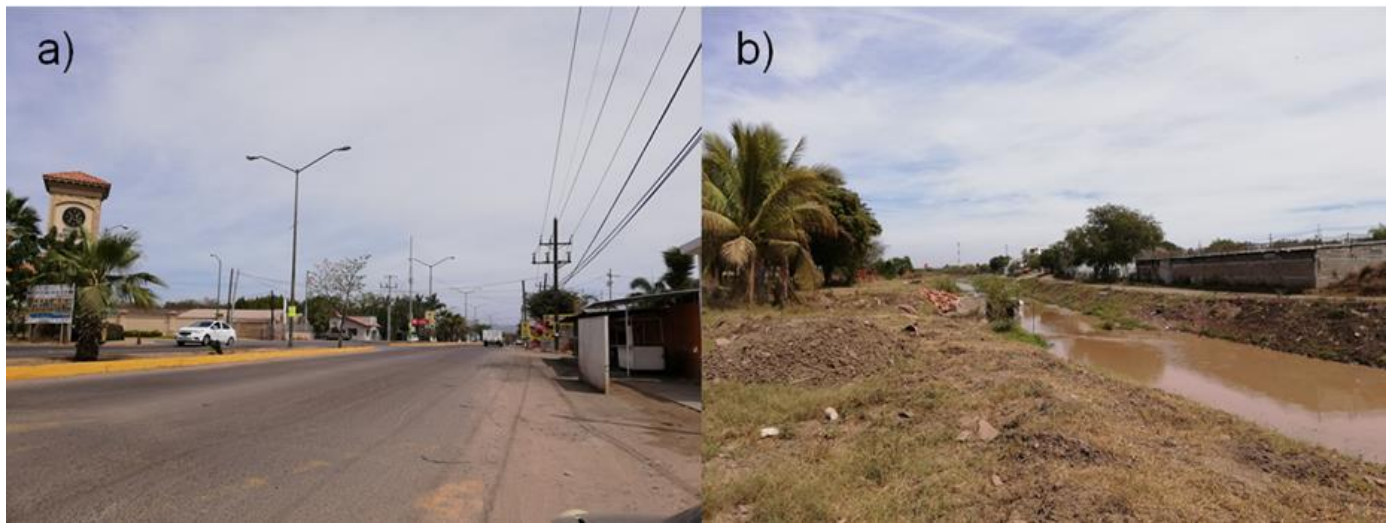

Fuente: Capturado por Belén P. P. Poblado Bacurimi y fraccionamiento Stanza Cantabria.

La Figura 6 está compuesta por un grupo de imágenes. En la imagen (a) se representa la distribución de fraccionamientos populares que dejan el patio de servicio hacia el exterior y la fachada principal hacia el interior, con la finalidad de que los muros traseros sean los que funcionen como elemento divisorio, dando la espalda a los asentamientos colindantes. En la imagen (b) sucede entre los mismos fraccionamientos populares, donde además aparecen canalizaciones. En la imagen (c) las fronteras con muros se repiten entre la parte trasera de los fraccionamientos populares para separarse de los

ACE, 14 (42) CC BY-ND 3.0 ES | UPC Barcelona, España | La fragmentación socioespacial de las urbanizaciones populares 16 en la periferia de la ciudad de Culiacán Rosales. DOI: http://dx.doi.org/10.5821/ace.14.42.8521 
espacios intersticiales. En la imagen (d) se aprecia la colocación de malla a lo largo de vialidades. La imagen (e) representa una de las técnicas de mercadotecnia empleada por las desarrolladoras de fraccionamientos populares que utilizan el cul de sac como diseño urbano, empleando una vialidad que funciona como distribuidora a los diferentes accesos, generando pequeños grupos de viviendas, en donde los vecinos tienden a privatizar de manera ilegal las vialidades colocando rejas en el único acceso y refuerzan la fragmentación entre un mismo desarrollo popular.

\section{Figura 6. División entre fraccionamientos populares}

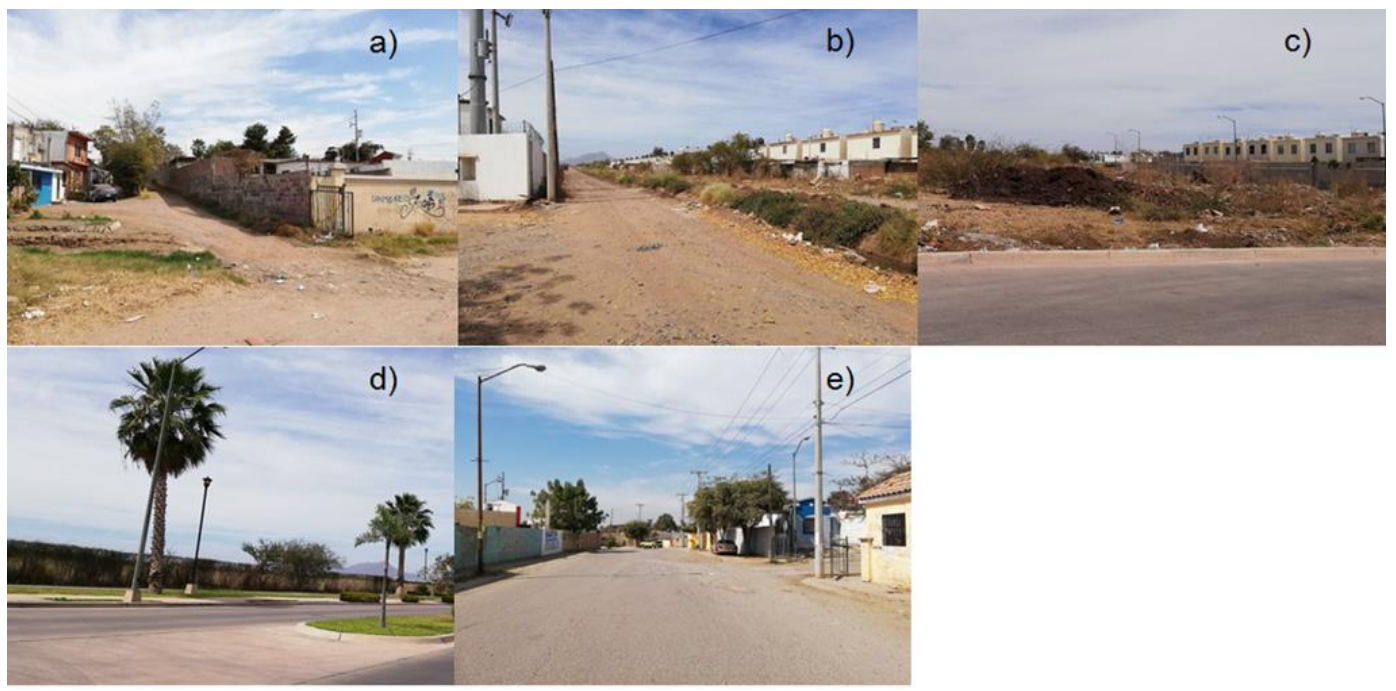

Fuente: Capturado por Belén P. P. (a) División entre fraccionamiento Villa Bonita y colonia Los Huizaches; (b) división entre los fraccionamientos Villas del Cedro y Stanza Cantabria; (c) Fraccionamiento Villas del Cedro, en colindancia con espacio intersticial; (d) Fraccionamiento Stanza Cantabria, en colindancia con espacio intersticial, separado por medio de malla, y (e) divisiones dentro de fraccionamiento Villa Bonita.

Además del aumento de la producción de barreras, otro elemento de distinción entre los diferentes tipos de asentamiento popular es el diferenciado suministro de servicios públicos y la falta de presencia del estado, mostrando abandono de la función de planificación urbana (Janoschka, 2002). Como afirman Kaztman (2000) y Kaztman y Retamoso (2005), el progresivo repliegue y la relación entre la población en situación de pobreza se vincula a la desaparición de los espacios de sociabilidad entre clases -que posibilitaba intercambios informales y una especie de agenda común- y la segmentación de la calidad de los servicios públicos, en particular al deterioro de la educación y la salud en los territorios que habitan. Y estructuralmente la diferenciación es resultado de la escasa posibilidad de integración de amplios grupos de la población al mercado laboral y de acumulación de recursos (Soldano, 2008).

\section{Conclusiones}

Las urbanizaciones populares son el tipo de poblamiento predominante. Se diferencian fácilmente del resto de unidades poblacionales de niveles socioeconómicos medio y residencial por el tipo de vivienda, la disponibilidad de servicios, equipamiento e infraestructura. A su vez, es clara la diferenciación con barreras entre los diferentes tipos de urbanizaciones populares. Es decir, incluso en un mismo tipo de asentamiento poblacional se colocan elementos que los separa y distingue entre ellos.

La fragmentación socioespacial a pequeña escala tiene signos que van en aumento, en particular por el empleo de barreras entre unidades poblacionales, aun tratándose del mismo nivel socioeconómico. 
Las urbanizaciones populares con más elementos divisorios son los fraccionamientos populares, que desde el inicio fueron construidos por promotores formales; también son los que ocupan mayor superficie de la ciudad y colindan con todos los tipos de urbanizaciones populares como los asentamientos de origen informal, colonias populares y poblados.

La ciudad de Culiacán Rosales, como ciudad intermedia, replica la fragmentación a pequeña escala, uno de los rasgos característicos de las metrópolis latinoamericanas. El caso analizado en la ciudad de Culiacán Rosales muestra que no solo se levantan fronteras con muros y mallas, entre las plazas comerciales, las urbanizaciones populares y los fraccionamientos, dirigidos a los grupos de ingresos medios y altos, sino también en los diferentes tipos de urbanización popular, dejando ver que el fenómeno de fragmentación urbana sigue en aumento, aunque presenta nuevas formas. Esta modalidad de crecimiento no solo impide la continuidad de la trama urbana, sino que acentúa la discriminación, el rechazo entre los diferentes grupos de población y evita el contacto con «el otro». Así, esta fragmentación socioespacial de las urbanizaciones populares propicia nuevas formas de habitar la ciudad que afectan a la población de manera diferenciada, perjudicándola con menos recursos, quedando limitada su integración a la ciudad en un entorno de muros y mallas, así como entorpeciendo el acceso a servicios y equipamiento.

\section{Autoría}

La primera autora ha participado en la redacción, elaboración de cálculos, planos y fotografías. Y la segunda autora ha colaborado en la redacción, asesoría, coordinación y revisión.

Conflicto de intereses: Las autoras declaran que no hay conflicto de intereses.

\section{Bibliografía}

Acosta, J. (2018). División social y fragmentación urbana, consecuencias de la distribucion espacial de la población y tipos de poblamiento. En J. Acosta (Ed.) División Social y Fragmentación Urbana en ciudades mexicanas (pp. 23-42). Culiacán Rosales: Editorial UAS.

Acosta, J. y Marmolejo, C. (2016). Análisis cuantitativo de la división social del espacio y la segregación en las ciudades mexicanas: caso Culiacán Rosales, Sinaloa, México. Ciudad Virtual y Territorio. Barcelona: CPSV, 221-232. Recuperado de https://upcommons.upc.edu/handle/2117/90895

Alvarado, R. y Stringher, M. (2011). Un acercamiento al fenómeno de la fragmentación socio territorial en la zona noroeste y noreste de la ciudad de Cuernavaca, Morelos. Revista Geográfica de América Central, 2, 1-15. Recuperado de https://www.redalyc.org/pdf/4517/451744820364.pdf

Baragona, S. (2019). Images from space help map extreme poverty. Science \& Health. Recuperado de https://www.voanews.com/science-health/images-space-help-map-extreme-poverty

Borsdorf, A. (2003). Cómo modelar el desarrollo y la dinámica de la ciudad latinoamericana. Eure, XXIX(86), 37-49. DOI: https://doi.org/10.4067/S0250-71612003008600002

Cerasoli, M. (2010). Periferias urbanas degradadas: transformación de los espacios y evolución del habitar: ¿cómo intervenir? ACE: Architecture, City and Environment, 5(13), 45-66. DOI: https://doi.org/10.5821/ace.v5i14.2505

Connoly, P. (2005). Tipos de poblamiento en la ciudad de México. Serie Metodología, Observatorio Urbano de La Ciudad de México, Universidad Autónoma Metropolitana.

ACE, 14 (42) CC BY-ND 3.0 ES | UPC Barcelona, España | La fragmentación socioespacial de las urbanizaciones populares 18 en la periferia de la ciudad de Culiacán Rosales. DOI: http://dx.doi.org/10.5821/ace.14.42.8521 
Díaz, F. (2006). Globalización, espacio urbano y fragmentación social. Los muros de la ciudad. En La ciudad fragmentada: Nuevas formas de hábitat. Servicios de Publicaciones, 43-64.

DZMM. (2015). Delimitación de las zonas metropolitanas de México 2015. Recuperado de https://www.gob.mx/conapo/documentos/delimitacion-de-las-zonas-metropolitanas-de-mexico-2015

Giglia, Á. (2014). Hacia una redefinición de la habitabilidad. Perspectivas téoricas y practicas de los habitantes. Aproximaciones a La Historia Del Urbanismo Popular. Una Mirada Desde México. 69-89.

Gómez, R. y Alvarado, R. (2016). Fragmentación física-material y las urbanizaciones cerradas en la Zona Metropolitana de Querétaro-México. Revista de Trabajo Social e Intervención Social, 21, 57-76. Recuperado de file://C:/Users/52667/Downloads/920-Texto\%20del\%20art\%C3\%ADculo-1959-1-1020161121.pdf

Guzmán, A., \& Hernández, K. (2013). La fragmentación urbana y la segregación social una aproximación conceptual. Revista Legado de Arquitectura y Diseño, (14), 41-55. Recuperado de https://www.redalyc.org/pdf/4779/477947373004.pdf

Hidalgo, R., Borsdorf, A. y Sánchez, R. (2007). Hacia un nuevo tejido rurbano: los megaproyectos de ciudades valladas en la periferia de Santiago de Chile. Ciudad y Territorio-Estudios Territoriales, XXXIX(151), 115.

IMPLAN. (2018). Instituto Municipal de Planeación.

INEGI. (2015). Instituto Nacional de Estadistica, Geografía e informática. Conteo Intercensal de población y vivienda.

Janoschka, M. (2002). El nuevo modelo de la ciudad latinoamericana: Fragmentación y privatización. EURE (Santiago), 28(85), 11-29. DOI: https://doi.org/10.4067/S0250-71612002008500002

Jiménez, E. (2016). La urbanizacion popular en Guadalajara. En É. Alcántar (Ed.), Aproximaciones a la historia del urbanismo popular. Experiencia en ciudades mexicanas (pp. 185-210). Ciudad de México: Coordinación Editorial de la Facultad de Arquitectura de la UNAM.

Kaztman, R. (2005). Seducidos y abandonados: El aislamiento social de los pobres urbanos. Reflexiones Sobre Su Naturaleza, Determinantes y Consecuencias. Montevideo (Documento Inédito).

Kaztman, R., \& Retamoso, A. (2005). Segregación espacial, empleo y pobreza en Montevideo. Revista de La CEPAL No No Abril. Recuperado de https://repositorio.cepal.org/bitstream/handle/11362/11004/1/085131148 es.pdf

Link, F. (2008). De la policentralidad a la fragmentacion en Santiago de Chile. Centro-H, 2, 13-24. Recuperado de https://www.redalyc.org/pdf/1151/115112535002.pdf

Mollenkopf, J. y Castells, M. (1991). Dual City: Restructuring New York. Russell Sage Foundation.

Navez-Bouchanine, F. (2001). Des villes entre fragmentation spatiale et fragmentation sociale: une approche critique de la notion de fragmentation. Vocabulaire de La Ville, Paris, Le Temps, 109-118.

ONU-HÁBITAT. (2012). Estado de las ciudades de América Latina y el Caribe. Rumbo a una nueva transición urbana. Por un mejor futuro urbano. Programa de Las Naciones Unidas Para Los Asentamientos Humanos, 196. Recuperado de https://flacso.edu.ec/cite/onu-habitat 2012 estadode-las-ciudades-de-america-latina-y-el-caribe-rumbo-a-una-nueva-transicion-urbana/

ACE, 14 (42) CC BY-ND 3.0 ES | UPC Barcelona, España | La fragmentación socioespacial de las urbanizaciones populares 
Pérez, N., Gil, F. y Bayona, J. (2017). La segregación socioespacial en Culiacán, México (2000-2010): ¿de la ciudad dual a la ciudad fragmentada? Estudios Demográficos y Urbanos, 32(3), 547-591. DOI: https://doi.org/10.24201/edu.v32i3.1660

Pinedo, J. y Lora, C. (2016). Hacia una tipología de asentamientos informales. ACE: Architecture, City and Environment, 10(30), 11-30. DOI: https://doi.org/10.5821/ace.10.30.3977

Prévot, M. (2000). Segregación, fragmentación, secesión. Hacia una nueva geografía social en la aglomeración de Buenos Aires. Economía, Sociedad y Territorio, II(7), 405-431. Recuperado de https://est.cmq.edu.mx/index.php/est/article/viewFile/437/890

Prévôt, M. (2001). Fragmentación espacial y social: conceptos y realidades. Perfiles Latinoamericanos, 19, 33-56. Recuperado de https://perfilesla.flacso.edu.mx/index.php/perfilesla/article/view/315/269

PMDUC, (2014). Índice socioeconomico de marginación y pobreza. Programa Municipal de Desarrollo Urbano de Culiacán.

RCMC. (2007). Reglamento de construcción del municipio de Culiacán.

Rodríguez, S. (2006). Los impactos urbanos de los fraccionamientos cerrados en la expansión urbana de la ciudad de Culiacán (Tesis de maestría). Universidad Autónoma de Sinaloa. Recuperado de http://148.228.173.140/topofilia/assets/tesis-sylviac.pdf

Rodríguez, S. (2018). Imaginario de la división social del espacio y la fragmentación en Culiacán Rosales. In J. Acosta (Ed.), División Social y Fragmentación Urbana. En Ciudades Mexicanas (pp. 4358). México: Editorial UAS.

Roldán, H. y Pérez, B. (2018). Fragmentación urbana en el sector sur de Culiacán. En J. Acosta (Ed.), División social y fragmentacion urbana en ciudades Mexicanas (pp. 59-78). Culiacán: Editorial UAS.

Rossi, A. (1999). Arquitectura en la ciudad (5ta Edición). Barcelona, España: Gustavo Gili, S.A.

Sabatini, F., Cáceres, G. y Cerda, J. (2001). Segregación residencial en las principales ciudades chilenas: Tendencias de las tres últimas décadas. EURE (Santiago), 27, 21-42. DOI: https://doi.org/10.4067/S0250-71612001008200002

Sassen, S. (1996). La ville globale. New York. Londres. Tokyo, Paris, Descartes \& Cie. Traduit de The global City, 1991.

Soldano, D. (2008). Vivir en territorios desmembrados. Un estudio sobre la fragmentación socioespacial y las políticas sociales en el Área Metropolitana de Buenos Aires (1990-2005). En A. Ziccardi (Ed.), Proceso de urbanización de la pobreza y nuevas formas de exclusión social (pp. 37-69). Recuperado de http://biblioteca.clacso.edu.ar/ar/libros/clacso/crop/ziccardi/04solda.pdf

SUN. (2018). Sistema Urbano Nacional. Recuperado de https://www.gob.mx/cms/uploads/attachment/file/400771/SUN 2018.pdf

Svampa, M. (2004). Fragmentación espacial y procesos de integración social "hacia arriba": Socialización, sociabilidad y ciudadanía. Espiral. Estudios Sobre Estado y Sociedad, 9(31), 55-84. Recuperado de https://www.redalyc.org/pdf/138/13803103.pdf

Tecco, C. y Valdés, E. G. (2006). Segregación residencial socioeconómica e intervenciones para contrarrestar sus efectos negativos: Reflexiones a partir de un estudio en la ciudad de Córdoba, Argentina. Cuadernos de Geografía, (15), 53-66. Recuperado de http://dialnet.unirioja.es/servlet/articulo?codigo=4014164\&info=resumen\&idioma=ENG 
Thuillier, G. (2001). Barrios cerrados en Buenos Aires: cuando la ciudad se convierte en país. Cahiers Des Amériques Latines, (35), 41-56. Recuperado de https://journals.openedition.org/cal/6534

Valdés, E. y Koch, M. (2009). Tendencias de segregación residencial en metrópolis latinoamericanas intermedias al inicio del siglo XXI. Porto Alegre (Brasil) y Córdoba (Argentina). Revista Lider, 15(11), 85104. Recuperado de http://ceder.ulagos.cl/lider/images/numeros/15/[LIDERVol15Año11-2009-ISSN0717-016574.-Tendenciasdesegregaciónresidencialenmetrópolis.pdf

Vidal, R. (1997). Metropolis en recomposicion: Elementos para una teoria de la fragmentacion urbana. 1-15. Recuperado de https://docplayer.es/76420756-Metropolis-en-recomposicion-elementos-parauna-teoria-de-la-fragmentacion-urbana.html 